\title{
DISASTER RESILIENT BUILT ENVIRONMENT: ROLE OF LIFELONG LEARNING AND THE IMPLICATIONS FOR HIGHER EDUCATION
}

\author{
Mohan SIRIWARDENA ${ }^{1}$, Chamindi MALALGODA ${ }^{2}$, Menaha THAYAPARAN ${ }^{3}$, \\ Dilanthi AMARATUNGA ${ }^{4}$ and Kaushal KERAMINIYAGE 5 \\ ${ }^{1}$ School of the Built Environment, University of Salford, The Cresent, Salford, M5 4WT, \\ United Kingdom \\ E-mail:M.L.Siriwardena@salford.ac.uk \\ ${ }^{2}$ School of the Built Environment, University of Salford, The Cresent, Salford, M5 4WT, \\ United Kingdom \\ E-mail:C.I.Malalgoda@edu.salford.ac.uk \\ ${ }^{3}$ School of the Built Environment, University of Salford, The Cresent, Salford, M5 4WT, \\ United Kingdom \\ E-mail: M.Thayaparan@salford.ac.uk \\ ${ }^{4}$ School of the Built Environment, University of Salford, The Cresent, Salford, M5 4WT, \\ United Kingdom \\ E-mail: R.D.G.Amaratunga@salford.ac.uk \\ ${ }^{5}$ School of the Built Environment, University of Salford, The Cresent, Salford, M5 4WT, \\ United Kingdom \\ E-mail: K.P.Keraminiyage@salford.ac.uk
}

Received 2 July 2012; accepted 18 January 2013

\begin{abstract}
Disasters cause considerable damage around the world every year. The built environment is significantly affected by disasters. Whilst the built environment is expected to withstand such occurrences, the construction industry is expected to play a pivotal role in reconstruction of damaged property and infrastructure. Such responses call for technological and managerial innovation. Therefore it is important that construction professionals receive continuous skill development to respond to disaster situations in order to build a disaster resilient built environment. Due to the complexities involved in and due to peculiar nature of disaster situations, lifelong learning is considered as an appropriate way of ensuring continuous education to the various stakeholders of disaster management. The paper reports preliminary findings from a European Commission funded research project aimed at modernising the higher education institutes to support lifelong learning in the built environment. The paper reports the key findings from the literature review and case study on disaster management, emphasising the role of lifelong learning in disaster management education. Empirical data collected as part of the workshop suggest that providing disaster management education as a degree programme is ineffective due to the complexity and multi-disciplinary nature of the subject. Further, the lack of involvement with the industry and the lack of research and development activities on disaster management by built environment professionals act as hindrance to effective disaster management education. In addressing the shortcomings on the existing approaches of disaster management education, this paper concludes that lifelong learning as the most appropriate approach to educate built environment professional in the context of disaster management.
\end{abstract}

KEYWORDS: Disaster; Education; Lifelong learning; Built environment 
REFERENCE to this paper should be made as follows: Siriwardena, M., Malalgoda, C., Thayaparan, M., Amaratunga, D. and Keraminiyage, K. (2013) Disaster resilient built environment: role of lifelong learning and the implications for higher education, International Journal of Strategic Property Management, 17(2), pp. 174-187.

\section{INTRODUCTION}

An increase in the intensity of disasters has been observed worldwide over the past decade resulting in higher number of mortalities, economic losses and social losses. Therefore, effective disaster management strategies are required to avoid or reduce the potential impacts of hazards, to assure prompt assistance to victims after an onset of a disaster, and to achieve timely recovery and reconstruction.

The built environment is an abstract concept used to describe the products of human building activity and includes any physical alteration to the natural environment (Lawrence and Low, 1990). Considering the impact of disasters on the built environment, both natural and manmade disaster cause massive destruction to built environment, thus obstruct social and economic development (Ginige et al., 2010). The recent disasters have clearly highlighted the vulnerability of the built environment and the lack of proactive measures for mitigation of such events (Bosher et al., 2007). In the recent years there has been a growing recognition that the construction industry and the built environment professionals have a vital role in contributing to society's improved resilience (Haigh and Amaratunga, 2010). Also highlighted is the fact that resilience should be systematically built into the whole design, construction and operation process and not simply added on as an afterthought (Bosher et al., 2007). Therefore, active and specialist contribution from the built environment professionals are vital for achieving overall disaster resilience of the built environment.

The increase in occurrences and the severity of the impacts of disasters suggest the essential need for education and training in subject disciplines which constitute the overall realm of disaster management. Education and training is an integral part of capacity build- ing in the disaster management discipline as trained personnel respond much better to different disasters and will take proactive measures of mitigation and prevention (IDKN, 2009). Therefore, specialised training is essential for all professionals who are engaged in the field of disaster management and resilience. Hence, it is of paramount importance to design and deliver the relevant education and training programmes to make the built environment professionals to prepare, mitigate and respond efficiently and effectively in a disaster situation. In this context, Higher Education Institutions (HEIs) have a key role to play in supplying specific skills and knowledge that are necessary to act proactively in such situations. Lifelong learning opportunities further enhance this provision as it will give an opportunity for the HEIs to act as continuing education centres in providing skills and knowledge in a dynamic environment (Thayaparan et al., 2010; Kaklauskas et al., 2012).

In addressing the lifelong learning needs of built environment education, the BELLCURVE (Built Environment Lifelong Learning Challenging University Responses to Vocational Education) research project focused on integrating the construction labour market skill needs into the modernisation agenda of the HEIs in Europe. BELLCURVE is a European Commission (EC) funded research project conducted by the University of Salford, UK, in collaboration with Vilnius Gediminas Technical University, Lithuania and Tallinn University of Technology, Estonia. The project aimed to develop a framework to make HEIs more responsive to the labour market skills needs while promoting lifelong learning among HEIs. The developed framework has been validated in the context of different built environment disciplines such as quantity surveying, disaster management, civil engineering and construction management. This paper focuses on 
disaster management both pre-disaster planning and post-disaster response, by analysing the lifelong learning needs for disaster management education.

Following the introductory section which briefly explained the rationale behind BELLCURVE research project, an overview of the evolving nature of disaster management concepts in relation to built environment and the need for disaster management education for the built environment professionals is presented through a synthesis of literature. The concept of lifelong learning is then introduced as lifelong learning approach has been recommended for disaster management education. The research methodology adopted for this paper is then presented. The empirical data and the secondary data related to existing approaches to disaster management education are discussed. The lifelong learning as an appropriate approach for disaster management education is then justified. Recommendations are provided for HEIs to accommodate lifelong learning within the education system.

\section{DISASTERS, THEIR EFFECTS AND MANAGEMENT}

Disasters carry the potential to cause devastation to human, built and natural environment and frequently interrupt economic and social development throughout the world (Kreimer, 2001). An increased intensity of disasters has been observed worldwide over the past decade resulting a higher number of fatalities, economic and social losses. To name few, Indian Ocean Tsunami (2004), Hurricane Kathrina in New Orleans (2005), earthquakes in Italy (2009), floods in Pakistan (2010), Haiti (2010), Japan (2011), and Hurricane Sandy (2012) have resulted in large scale losses and damages. The economic losses caused by disasters are of twofolds, namely direct and indirect. Direct losses include financial cost of the physical damages, destruction of communities and their negative impacts on families (Kreimer, 2001). According to ISDR (2011) in 2010, 373 natural disasters caused the death of over 296,800 people, affected nearly 208 million others and cost nearly US $\$ 110$ billion. The earthquake in Haiti and the Russian heat wave were the two most fatal disasters which made 2010 the deadliest years of two decades. The recent earthquake that hit Japan caused more than 28,000 fatalities (USGS, 2011) and it further led to multiple disasters of tsunami and radiation leak. The above statistics have challenged the resilience and emergency arrangements currently in place, and reinforced the need for proactive disaster management. Therefore, a well-planned system is necessary to reduce the consequences of these disasters (Pourezzat et al., 2010).

The term 'disaster' is interpreted differently by different authors and institutions. Smith (2004) viewed disasters as a social phenomenon that occurs when a community suffers exceptional, non-routine, levels of disruption and loss. He further explained that a disaster can occur as a consequence of a hazard which is naturally occurring or as a result of a human induced process or an event with the potential to create a loss. When a hazard becomes the active reality and when damage relevant to man is inflicted, it becomes a disaster (McDonald, 2003). Although, the origin and the causes of disasters are diverse, the consequences to the society are more or less similar. These include, extensive loss of life; economic losses; destruction of the built and natural environment; and, widespread disruption to local institutions and livelihoods (Haigh and Amaratunga, 2010). These impacts can vary depending on the type of the disaster and the economic conditions of the area that was struck by the disaster (McDonald, 2003).

Smith (2004) too has argued that the relationship between hazard and risk are very much affected by human conditions and actions. It is understood that all individuals and communities are vulnerable to hazards in varying degrees and all have inherent capacities to reduce the vulnerabilities (Ginige et al., 2009). As such the consequence of a disaster would be different if the same event happens in different circumstances, and may 
also depend on where it took place and how it was perceived (McDonald, 2003). In fact the consequences of a disaster are much less severe if it happens in a place where people are well protected, whereas the consequences are considerably more significant if it happens in a poorly protected environment. Accordingly, disaster risk can be reduced either by decreasing the hazards and/or vulnerabilities and/or by increasing the capacities. Therefore, disaster risk reduction should incorporate measures to curb disaster losses by addressing hazards and people's vulnerability to them, throughout the disaster management cycle (Palliyaguru and Amaratunga, 2008).

Disaster management can be defined as a "collective term encompassing all aspects of planning for and responding to disasters, including both pre and post-disaster activities" (CERO, 2004). It may refer to the management of both the risks and consequences of disaster. Disaster management can be depicted as a cycle of inter-related activities. According to Warfield (2004), the disaster management cycle illustrates the ongoing process by which governments, businesses and civil society plan for and reduce the impact of disasters, react during and immediately following a disaster, and take steps to recover after a disaster has occurred. According to Kawata (2001), disaster management can be divided into four parts such as emergency response and relief; recovery and reconstruction; mitigation and preparedness. Therefore, to reduce consequences of disasters and to achieve resilience, it is important to focus on all phases of the disaster management cycle.

The built environment consists of all forms of buildings and other physical infrastructure. Given the essential role such facilities play in everyday life of human beings, any destruction to built environment can disturb the regular functioning of the human society. In this context, due to significant risks posed to society by the increasing number of disasters, the importance of achieving a disaster resilient built environment has been widely recognised. Therefore, it is of paramount importance to design, build and operate the built environment in a way that it can withstand the adverse impacts of hazards. In this context, a disaster can be considered as an engineering failure in terms of the design, construction and/or operation of the built environment, where the impact would have been much lesser if the built environment were designed and built appropriately incorporating mitigation. In this regard, Kulatunga (2010) argued that natural disasters can also be attributed to human action in circumstances such as increasing the vulnerability of people towards extreme physical events by constructing unsafe buildings, poor urban planning, poverty and dense population.

In this context, increasing the capacity of the built environmental professionals by providing a disaster management education is vital in responding to disasters. Accordingly, the next section highlights the role of built environment professionals in responding to disastrous situations.

\section{DISASTER MANAGEMENT EDUCATION FOR BUILT ENVIRONMENT PROFESSIONALS}

The built environment involves professionals with multi-disciplinary backgrounds. Few to name are architects, engineers, surveyors, urban planners, property and facility managers, environmental specialists, sociologists, policy makers, medical specialists and disaster management specialists. Knowledge and expertise of these professionals at various stages of the construction and post-disaster reconstruction processes are essential to achieving the disaster mitigation and resilient aspects of the built environment. In addition to the specialisation of each discipline, interaction and collaboration between the multiple disciplines are also vital in meeting the complex demands of disaster management.

The importance of the role played by the built environment professionals in the reconstruction activities following disasters has been well documented, though it may not be significantly visible during immediate relief 
attempts. Post-disaster reconstruction, in particular, has been the subject of a continuous discussion with particular emphasis on developing countries that are less able to deal with the causes and impacts of disasters (for examples see Karim, 2004; Lizarralde and Boucher, 2004; Nikhileswarananda, 2004 and Young, 2004). Thus, the importance of improving the capacity of the construction professionals to address post disaster reconstruction challenges is widely recognised (Ofori, 2002). Within the disaster management cycle, construction professionals are typically engaged in a range of critical activities such as: construction of temporary shelters after the disaster; restoration of public services (e.g. hospitals, schools, water supply, power, communications, environmental infrastructure and state administration); and securing income earning opportunities for vulnerable people in the affected areas (World Bank, 2001). Further, there is growing recognition that the construction professionals have a valuable role to play in finding and promoting rational, balanced solutions to what remains an unbounded threat (Sevin and Little, 1998) and that the construction industry has a much broader role to anticipate, assess, prevent, prepare, respond and recover from disruptive challenges. Pena-Mora (2005) suggests construction professionals have a key role to play within the role of disaster management because they are involved in the construction of the infrastructure, and therefore should also be involved when an event destroys that infrastructure. He specifically emphasises that construction professionals possess valuable information about their projects, and that information can be critical in disaster preparedness, response and recovery. Sevin and Little (1998) further suggest that computerised building plans, structural analysis programs, and damage assessment models may all facilitate rapid rescue and recovery of victims in the aftermath of a disaster, and these all require the active involvement of the construction professionals. The growing recognition of Building Information Modelling (BIM) as an advanced use of information and communication technologies to achieve integrated data modelling and stake- holder collaboration is also noteworthy in this regard.

The role of the built environment professionals in disaster management has been highlighted as an important aspect and it demands disaster management education and training to such professionals in order to be effective in their roles during pre-disaster planning and post-disaster response. Further, dynamic and complex nature of the disaster management environment would require capacity building in the construction sector, strengthening of infrastructure and closer communication and collaboration between various stakeholders (Chang et al., 2010). The level of preparedness and education of the exposed country and community influences the magnitude of the impact of disasters (Rouhban, 2011). In this context, it is important to educate the built environment professionals involved in disaster management activities with the appropriate knowledge and skills. Higher education institutions having a critical role in the development of citizens and leaders at all levels of private and government organisations required to respond effectively to the needs and challenges of a disaster management environment and required to take up the responsibility of educating, training, and supporting the disaster response (McClellan, 2006). Thus, higher education institutions need to play a critical role in providing appropriate knowledge and skills to the built environment professionals to be effective in disaster situations.

\section{CONCEPT OF LIFELONG LEARNING}

The concept 'lifelong learning' has been used often to describe adult learning. Today it is used increasingly as a concept of learning at different ages, as a life-course process (Niemi, 2009). It draws attention to the learning that takes place in the spaces surrounding activities and events with a more overt formal purpose, and takes place in a much wider variety of settings than formal education or training (Eraut, 1985). It can also be considered as a complementary partner to learning from ex- 
perience, which is usually construed more in terms of personal than interpersonal learning. When a person is faced with a situation in which old knowledge and skills are no longer adequate, and which require new knowledge and new skills a need for a lifelong learning arises (Xiaozhou, 2001). In such instance, they are expected to upgrade their knowledge and skills either by attending a formal course or by informal means.

In the context of disaster management lifelong learning practices are increasingly seen as an approach to gain knowledge and skills. General awareness of the need for the development of lifelong learning policies, both at national and international levels, has been dated from the period immediately after World War II (Kallen, 2002). A rapid expansion has been observed subsequently on various forms of education such as in-house training, adult education and vocationally oriented training. The changing nature of work and the labour market have been identified as one of the forces emphasising the need for continued upgrading of work and life skills. The demand is for a rising threshold of skills as well as for more frequent changes in the nature of the skills required (OECD, 2004). To manage this need, individuals are expected to adopt the flexibility of being able to transfer skills and competences between jobs in respect of lifelong learning policy (Evans and Kersh, 2004).

The concept of lifelong learning as an educational strategy emerged some three decades ago, through the efforts of the Organisation for Economic Co-operation and Development (OECD), United Nations Educational Scientific and Cultural Organisation (UNESCO) and the Council of Europe. It was also agreed by these three bodies that the initial education and training needed to be followed through lifelong learning are accessible to all citizens, irrespective of their social or economic status. OECD (2003) defines lifelong learning as "all learning activity undertaken throughout life, with the aim of improving knowledge, skills and competences within a personal, civic, social and/or employment-related perspective".
Lifelong learning has a particular emphasis on learners' initiative, activity and creativity in the studies and attaches individuals' capacity to accept continuous education by making varied types of knowledge and skills available to meet their needs throughout the life cycle (Xiaozhou, 2001). Equipping students with the skills, knowledge, habits and attitudes that they would require in order to become lifelong learners is of paramount importance (Cropley and Knapper, 1983). This paper emphasises the importance of adopting lifelong learning as an appropriate approach for disaster management education.

\section{RESEARCH METHODOLOGY}

Review of literature, an international research workshop and a group validation exercise were the main ingredients which formed the methodology of this research. As the intention of this research was to understand the role of lifelong learning for disaster management education, an in-depth understanding about existing approaches to Disaster Management education, their relative advantages and disadvantages was required. This requirement triggered the necessity to take a qualitative methodological approach to the research. Accordingly, the research was designed to capture the expert knowledge of disaster management education providers (academics, researchers and disaster management trainers). Expert knowledge about this subject is scattered, and there are no universally accepted processes / methods or good practice guidelines in providing disaster management education. As it is important to reflect upon different processes / methods and good practices in disaster management education, while debating about their relative advantages / disadvantages, an open discussion forum in the mode of an international research workshop was identified as the best data collection strategy for this research. The literature review strengthened background knowledge with regard to the existing approaches of providing disaster management education. As a result, the need and the benefits of life- 
long learning for disaster management were established. Empirical evidence was gathered through an organised workshop as part of an international research conference on disaster resilience. The conference brought together many who possess expertise related to disaster resilience in built environment. The above mentioned research workshop of the BELLCURVE project was therefore organised as part of this conference, to which selected participants representing a multitude of stakeholders on disaster management education were invited. The workshop was attended by 15 participants comprising EU and international academics, researchers and representatives of government and semi-government organisations related to built environment and disaster management. Such a group was selected in order to benefit from their diverse expertise in the disaster resilience area, thereby providing the much needed multi-faceted data for this research.

Current approaches to disaster management skills acquisition and the role of HEIs in providing lifelong learning in the context of disaster management were thoroughly discussed during the workshop. The participants were divided into two breakout groups to discuss the issues at a greater depth. At the end of the workshop, two leaders of the breakout groups summarised their findings to the audience. The breakout session and the discussions were audio recorded for further analysis and the feedback was also captured via notes made on flipcharts. Detailed transcripts were prepared and the transcripts were subjected to a content analysis to draw findings of the discussion.

The workshop findings related to the current approaches to disaster management were validated by comparing with the literature review. Recommendations suggested during the workshop on how HEIs can contribute to provision of lifelong learning in the context disaster management in the built environment were validated through a group validation exercise in the form of an organised meeting of panel of experts comprising of built environ- ment disaster management educationalists of HEIs and researchers.

The following sections present the discussions based on both primary and the secondary data.

\section{EXISTING APPROACHES TO DISASTER MANAGEMENT EDUCATION: RESULTS AND DISCUSSION}

Disaster management is a multi disciplinary subject area which consists of subjects such as science, engineering, architecture, and involves non-engineering aspects such as gender, conflicts, climate change, governance, public policy, economics, education, agriculture etc. (Amaratunga et al., 2011; Shaw, 2008). Therefore, multi institutional or faculty involvement is essential for delivery of successful disaster management programmes. Due to the complexity and multi-disciplinary nature of the subject, educating disaster management has become a challenge. Thus, disaster management education needs to be carefully designed in such a way that it would be flexible and be able to customise to meet the situational demands. This section compares and contrasts the empirical and secondary data collected on different approaches of disaster management education in the built environment. The workshop findings are presented first followed by the literature which validates the findings derived through the workshop.

The key existing approaches to disaster management education identified through the workshop were the undergraduate/ postgraduate programmes conducted by the HEIs; final project/ dissertation in undergraduate and postgraduate programmes; CPDs and short courses conducted by HEIs, professional bodies and other institutes; widely available knowledge on the world wide web; other traditional modes like text books, magazines and other publications; and learning by experience. These approaches are discussed below linking with the relevant literature as part of the validation process. 
Undergraduate/postgraduate programmes conducted by HEIs: Workshop highlighted the possibility of introducing disaster management as an undergraduate or postgraduate level degree programme. It was argued that most of these programme focus on specific aspects of disaster management such as social, environmental, technical etc. failing to cover the multi-disciplinary nature of the disaster management disciplines. Therefore, such university based degree programmes are generally characterised as a shortcoming due to the lack of multi-disciplinary nature those degrees offer and the lack of involvement with the industries, professional bodies and communities.

Various authors have highlighted the possibility of introducing disaster management as an undergraduate or post graduate degree programme. For instance, Shaw (2008) highlighted the possibility of introducing disaster management as an undergraduate or postgraduate level degree programme. Some of the universities have already introduced these degree programmes to their students. For an example, Hulse and Moseley (1998) designed an undergraduate degree course aimed at meeting the educational and practical needs of graduates who intend to pursue careers within the field of disaster management which claimed to be multi-disciplined content, innovative structure and mode of delivery, and in international perspective. Similarly, more universities such as University of Salford in UK are conducting postgraduate degree courses related to the field of disaster management. As pointed out in the workshop discussion above, the university based degree programmes lacks the multidisciplinary nature and collaboration with industries, professional bodies and communities. As such, providing a degree programme on disaster management was not seen as an effective way of knowledge delivery, mainly due to the multi-disciplinary nature of the subject. Instead it was suggested that incorporating the subject of disaster management into the existing built environment programmes will enhance the knowledge on disaster management across different disciplines.
Disaster management module at undergraduate/postgraduate level: Considering the shortcoming in providing disaster management education as a separate degree, incorporating disaster management as a module to existing curricula at undergraduate and postgraduate levels has been identified as a better approach to teach disaster management across different built environment disciplines. Different built environment practitioners need different levels of skill sets in carrying out their duties in disaster scenarios. Therefore on one hand, by incorporating disaster management as a module across the built environment programmes will provide better opportunity to introduce the knowledge and skills required in the specific field of study. On the other hand, it will comparatively restrict the extent of the knowledge provision on disaster management when teaching disaster management as modules rather than as a programme.

In support of that Shaw (2008) also mentioned that including disaster management as a module in the regular undergraduate or postgraduate curriculum is one way of educating the professionals with such knowledge. This was further supported by Rivera and Miller (2008) and highlighted the need of encouraging and understanding the risks posed by disasters as a part of educational strategies to raise civic awareness by introducing into lower-level undergraduate education within the general education curriculum at institutions of higher education. This would enable institutionalisation of education in the field of disaster management and the curriculum should be designed to introduce disaster management modules for both school and university students (Seneviratne et al., 2010). Due to multifaceted nature of the subject area, providing thorough subject knowledge would be a problem. However, this would enable the learner to gain knowledge of disaster management which are mostly related to their degree programme.

CPDs and short courses conducted by HEIs, professional bodies and other institutes: Continuing Professional Development (CPD) is one of the popularly recognised routes 
for skills and knowledge acquisition. Workshop highlighted the importance of organising CPDs and short courses on disaster management. Different aspects of disaster management can be addressed depending on the disciplines of the professionals in the field of built environment. HEIs who involve in research related to disaster management are in advantageous positions to disseminate their disaster research findings to the industries and professionals through CPDs. On the other hand professional bodies, construction organisations and other institutes such as NGOs can also share their experiences related to disaster management with HEIs through organised CPDs and short courses. The low level of engagement HEIs have with the industries, professional bodies and communities was pointed as a major obstacle for this knowledge sharing practices. If the engagement is strengthened, then the provision of disaster management education to the built environment professionals through CPDs and short courses will be more effective than providing the same through curriculum or modules.

Considering the flaws in the provision of disaster management education through regular courses, it was suggested to provide the knowledge through short courses. In favouring this Shaw (2008) also agreed that short courses are another way of providing disaster management knowledge to the learners. Professional bodies generally conduct these short courses and workshops to their members as part of the continuous professional development (CPD) commitments. An example is the Royal Institution of Chartered Surveyors in the UK providing training to surveying professionals on cultural, gender, security, legal and humanitarian aspects of post disaster conditions (RICS, 2011), and further aims to provide training to humanitarian sector on land and built environment issues related to disaster management. However, in the context of current higher education system providing short courses to respond to the labour market requirements is not either popular or cost effective, even though HEIs have the ca- pacity to deliver such programmes to enable the learners to continually update their skills and knowledge. Rouhban (2011) also argued that education for disaster management is not a one-off affair but a continuing process which requires careful consideration of society's changing needs. The lifelong learning is, therefore, increasingly been viewed as a way of addressing the challenges of disaster management education which is in general complex, multi-faceted, interdisciplinary and dynamic in nature.

Research programmes and projects at HEIs: Another way of acquiring the skills and knowledge is through the research programmes such as undergraduate and postgraduate dissertations, doctoral studies and research projects. In some universities the built environment students gain more knowledge on disaster management when doing their project dissertations as part of either undergraduate or postgraduate programmes. The empirical evidences revealed at the workshop indicates that research conducted at universities provide immense opportunities for the students to engage with the industry practitioners; professional bodies and other relevant organisations related to the field of disaster management.

Georgetown University and Fritz Institute (2003) emphasised that collaboration between higher education institutions, industry practitioners, professional bodies and other humanitarian organisations is essential in order to promote improved training and education. Therefore, facilitating engagement with such entities as part of the research programmes and projects would be beneficial. Further staff exchange programme, placements or secondments for students and professional accreditations were highlighted as a way of facilitating engagement opportunities.

The element of research and development has been pointed out as another approach to disaster management learning in literature. Disaster management is an evolving discipline which requires continual update of new knowledge created through academic research, this will lead to the optimal linking of teach- 
ing and research (Amaratunga et al., 2011; Seneviratne et al., 2010). Thus universities are required to carry out research which would be multidisciplinary in nature with a mix of engineering and socio economic considerations and be linked to urban development, risk reduction and on operational issues related to disaster management (Erdik, 1999). One of the expectations of this approach is that the transfer of research knowledge to teaching will in turn improve industry practices.

Widely available knowledge on the World Wide Web: Majority of the research outcomes related to disaster management and resilience are widely available online and professionals can easily be directed to such resources to gain further knowledge. Nowadays, internet has become a part of everyone's life as a most accessible source for knowledge gaining. Therefore, World Wide Web is identified as an approach for professionals to gain knowledge on various aspects of disaster management. With the advancement of the technology people tend to surf through web when they need to learn something new. Much information on the web is freely available and basic knowledge can be gained through reading a publication or an article via internet. HEIs and other research organisations conducting research related to disaster management widely disseminate the knowledge through web and number of disaster related journals is now providing access to download articles online. Blogs or web based forums provide immense opportunity to share and discuss various issues related to the field of disaster management. As such, these web based professional forums will help the professionals in the built environment to gather or discuss the timely burning issues related to the field of disaster management. It was suggested that HEIs can be a facilitator by developing a platform exclusively for specific built environment professions to discuss on issues related to disaster management.

Other traditional modes like text books, magazines and other publications: Text books are one of traditional modes for knowledge acquisition where academics con- tribute to majority of textbooks. Many books, magazines and other publications are widely available in the field of disaster management. Most of these academic publications are accessible for the students of HEIs but little or no access is available for the built environment professionals. This was highlighted in the workshop that HEIs need to take necessary measures to make academic publications, though not limited to disaster management, widely accessible beyond their students to enable the professionals to gain disaster management education.

Learning by doing: Another way of acquiring disaster management skills is by way of learning by doing. By engaging in disaster related planning, designing, construction and re-construction, built environment professionals can gain knowledge and skills on disaster management.

The next section justifies the appropriateness of lifelong learning as a better approach for disaster management education. The justification provided below is followed by the recommendations for $\mathrm{HEI}$ s to accommodate lifelong learning within the education system. Those recommendations were derived from the workshop findings and have been validated through organised meeting of panel of experts.

\section{LIFELONG LEARNING AND DISASTER MANAGEMENT}

The learning process can mainly contain three classified elements namely formal, informal and non-formal learning. In short, formal learning is achieved through organised programmes delivered through schools and other providers and is recognised through a qualification or part of a qualification; non-formal learning is achieved through an organised programme or instruction, but is not recognised through a qualification; and informal learning is achieved outside the organised provision (OECD, 2004). Lifelong learning generally includes all of these three elements in its learning system.

The higher education institutions largely adopt formal learning approaches. Therefore 
it is a challenge for the HEIs to respond to the frequent and continuous changing needs solely thorough the facilitation of formal learning approaches. Thus, promotion of lifelong learning in higher education institutions would require changes in teaching methods with conventional students studying for traditional degrees (Cropley and Knapper, 1983). It has been suggested that the HEIs are required to accommodate a lifelong learning model within their educational system in order to be effective in responding to the labour market requirements in disaster situations. To support this approach of lifelong learning, various recommendations were suggested through the workshop. Those suggestions include virtual learning and knowledge sharing; franchise system to manage and deliver the programmes; networking and collaboration. If these suggestions, which are discussed below, can be incorporated within the higher education system, it will help HEIs to provide lifelong learning for disaster management education.

\subsection{Validated recommendations from the workshop}

'Teaching' lifelong learning is not always seen as realistic. Therefore, discussions were made how HEIs, who generally engage with the learners starting from their higher education level until the course duration, can provide lifelong learning. Lifelong learning itself indicates learning throughout life. Thus a limited engagement with HEIs is one of the major obstacles for HEIs to provide lifelong learning. Therefore, 'through-life studentship' has been realised as an important recommendations for HEIs, where higher education governance should explicitly facilitate this engagement.

The following recommendations were derived to accommodate lifelong learning provision within the higher education systems.

Short programmes such as CPDs for specific skill requirements: Offering short programmes, tailored for specific skill requirements, to the built environment professionals who are practising in the industries was identified as a way of engaging with the profession- als beyond the duration of their studentship. Conducting short programmes, mainly online based, will encourage learners to engage with HEIs and this in turn will facilitate lifelong learning. As discussed earlier, as providing short courses to respond to the labour market requirements is not either popular or cost effective, it was suggested that it could be achieved with the involvement of the professional bodies. Professional bodies usually conduct CPD programmes to their members. Encouraging professional bodies to conduct CPDs on different types of add on skills to perform disaster management activities would be beneficial for the professionals to learn disaster management

Invite experts from industry / professional bodies to deliver short courses and lectures: Inviting industry practitioners and professional bodies to deliver short courses or guest lectures was highlighted as a great opportunity for the students to get an exposure to the industry and will enhance their level of confident in their respective professions. This also provides an opportunity for the existing professionals to share their experiences with the potential professionals. This practice will improve the level of engagement HEIs has with the built environment professionals and in the long run the collaboration would facilitate a lifelong learning among HEIs.

Online mode of knowledge delivery and sharing: It was pointed out that the distance mode of education would be preferable to the built environment professionals compared to face-to-face session due to the time constraints and geographical dispersion. Though traditional mode of delivery, which is face-toface, was accepted as the most effective way of learning by the students, it is not considered favourably by those who are working in the industry. Thus, despite the effectiveness of this mode, the face to face delivery of courses was identified as an obstacle for lifelong learning opportunities. Accordingly, the workshop findings suggested online learning or distance learning mode to deliver lifelong learning to the built environment professionals. Blogs and 
online forums can be used as the platforms for knowledge sharing. Even though, these kinds of forums are already in place within most of the HEIs, they are largely developed on personal basis rather than on institutional basis. Formalising this type of virtual engagement will not only benefit the HEIs to gain an upto-date knowledge but also expand the level of collaboration between HEIs and other professional and industrial bodies.

Further, HEIs can be the facilitators for online knowledge base, as they undertake research and development activities within the institutions. The knowledge hub can be based on the research findings on disaster management and can be specific to built environment professions. In general, HEIs undertake extensive research related to disaster management in the form of doctoral studies or funded projects. However, having taken lot of efforts in producing outcomes and research findings, the publications of such results are generally limited to internal access. This trend should be modernised, as to make the research outcomes accessible to a wider community at least by targeting the specific beneficiary groups, so that it can benefit in terms of lifelong learning.

Franchise system: Another solution identified was to introduce a franchise system. A centralised body to act as a main hub for disaster management education would be ideal, when this body is linked to various centres of excellences, and in a position to deliver the knowledge by appropriately retrieving the knowledge or by delivering the knowledge in person. It was suggested that an academic network related to disaster management can initiate a franchise system as they do have expertise in various aspects of disaster management education.

Collaboration with HEIs, industries, professional bodies and communities: Lack of collaboration between HEIs, industries, professional bodies and communities was highlighted as a major obstacle for lifelong learning opportunities. Though, collaboration activities take place within HEIs at various levels, there is no formalised way of engaging with different entities. This can be achieved through existing network such as Alumni. Most of the leading participants in the profession are likely to be alumni of the universities and therefore universities can take the advantage of these leading professionals in the industry to share knowledge. A similar network customised for built environment professionals or a more formalised version of this network was recommended as it can help the HEIs to get engaged with former students who can share or update the HEIs with current / future labour market requirements in relation to disaster management.

\section{CONCLUSIONS}

The paper discussed the impact of disasters on the built environment and explained the role of built environment professionals in managing disasters. Due to the complex and peculiar nature of disaster situations, built environment professionals are expected to possess specific skills and expertise. Therefore, it is vital that they develop their capacity in preparing, mitigating and responding effectively to disaster situations. A disaster management education is therefore essential in making them more responsive to disaster events.

The role of higher education institutions in providing disaster management education was recognised. Empirical data collected as part of the workshop suggest that providing disaster management education as a degree programme is ineffective due to the complexity and multi-disciplinary nature of the subject. Further, the lack of engagement with the industries, professional bodies and communities act as hindrance to effective disaster management education. In addressing the shortcomings on the existing approaches of disaster management education, this paper concludes that lifelong learning as the most appropriate approach to educate built environment professional in the context of disaster management. Considering the challenges in accommodating lifelong learning within higher education system, recommendations were also suggested to support the lifelong learning agenda among higher education institutions. 


\section{ACKNOWLEDGEMENT}

BELLCURVE research project has been funded with support from the European Commission. This publication reflects the views only of the authors, and the Commission cannot be held responsible for any use which may be made of the information contained therein.

\section{REFERENCES}

Amaratunga, D., Siriwardena, M., Malalgoda, C., Pathirage, C. and Thayaparan, M. (2011) Lifelong learning needs for disaster management education in the built environment. In: Amaratunga, D., Haigh, R., Keraminiyage, K., Kulatunga, U. and Pathirage, C. (eds.), Proceedings of International Conference on Building Resilience 2011: Interdisciplinary approaches to disaster risk reduction, and the development of sustainable communities and cities, Kandalama, Sri Lanka, 19-21 July 2011.

Bosher, L., Dainty, A., Carrillo, P. and Glass, J. (2007) Built-in resilience to disasters: A pre-emptive approach, Engineering, Construction and Architectural Management, 14(5), pp. 434-446. http://dx.doi. org/10.1108/09699980710780746

CERO (2004) Disaster management for students: managing disasters. [Online] Barbados, Central Emergency Relief Organization. Available at: http://cero.gov.bb/ pages/students.html [accessed 13 May 2010]

Chang, Y., Wilkinson, S., Potangaroa, R. and Seville, E. (2010) Interpreting resourcing bottlenecks of post Wenchuan earthquake reconstruction in China, International Journal of Strategic Property Management, 14(4), pp. 314-331. http://dx.doi.org/10.3846/ ijspm.2010.24

Cropley, A. and Knapper, C. (1983) Higher education and the promotion of lifelong learning, Studies in Higher Education, 8(1), pp. 15-21. http://dx.doi.org/10.1080/ 03075078312331379081

Erdik, M. (1999) Academic, professional and technical institutions. In: Ingleton, J. (eds.), Natural disaster management: A presentation to commemorate the international decade for natural disaster reduction (IDNDR) 1990-2000, Tudor Rose Holdings Limited, Leicester, pp. 234-235.

Eraut, M. (1985) Knowledge creation and knowledge use in professional contexts, Studies in Higher Education, 10(2), pp. 117-133. http://dx.doi.org/10.1080/03 075078512331378549

Evans, K. and Kersh, N. (2004) Recognition of tacit skills and knowledge: Sustaining learning outcomes in workplace environments, Journal of Workplace Learning, 16(1/2), pp. 63-74. http://dx.doi. org/10.1108/13665620410521521

Georgetown University and Fritz Institute (2003) Challenges of disaster management education. [Online] Washington, Georgetown University and Fritz In- stitute. Available at: http://www.fritzinstitute.org/ GeorgetownEducation.htm [accessed 13 May 2011]

Ginige, K., Amaratunga, D. and Haigh, R. (2009) Mainstreaming gender in disaster reduction: why and how?, Disaster Prevention and Management, 18(1), pp. 23-34. http://dx.doi.org/10.1108/09653560910938510

Ginige, K., Amaratunga, D. and Haigh, R. (2010) Developing capacities for disaster risk reduction in the built environment: Capacity analysis in Sri Lanka, International Journal of Strategic Property Management, 14(4), pp. 287-303. http://dx.doi.org/10.3846/ ijspm.2010.22

Haigh, R. and Amaratunga, D. (2010) An integrative review of the built environment discipline's role in the development of society's resilience to disasters, International Journal of Disaster Resilience in the Built Environment, 1(1), pp. 11-24. http://dx.doi. org/10.1108/17595901011026454

Hulse, R. and Moseley, L. (1998) Educating for disasters: An international engineering first, European Journal of Engineering Education, 23(2), pp. 233-241. http:// dx.doi.org/10.1080/03043799808923501

IDKN (2009) Planning for safer tomorrow. [Online] India, India Disaster Knowledge Network. Available at: http://www.saarc-sadkn.org/countries/india/major_safe.aspx [accessed 13 May 2011]

ISDR (2011) Killer year caps deadly decade - reducing disaster impact is "critical" says top UN disaster official. [Online] Geneva, United Nations International Strategy for Disaster Reduction. Available at: http:// www.unisdr.org/archive/17613 [accessed 11 April 2011]

Kaklauskas, A., Daniūnas, A., Amaratunga, D., Urbonas, V., Lill, I. Gudauskas, R., D‘Amato, M., Trinkūnas, V. and Jackutè, I. (2012) Life cycle process model of a market-oriented and student centered higher education, International Journal of Strategic Property Management, 16(4), pp. 414-430. http://dx.doi.org/10.3846/1648715X.2012.750631

Kallen, D. (2002) Lifelong learning revisited. In: Istance, D., Schuetze, H. G. and Schuller, T. (eds.), International Perspectives on Lifelong Learning: From Recurrent Education to the Knowledge Society. The Society for Research into Higher Education and Open University Press, Buckingham, pp. 32-38.

Karim, N. (2004) Options for floods and drought preparedness in Bangladesh. In: Proceedings of the Second International Conference on Post-disaster reconstruction: Planning for Reconstruction, 22-23 April 2004. Coventry University, UK.

Kawata, Y. (2001) Disaster mitigation due to next Nankai earthquake tsunamis occurring in around 2035. [Online] Kyoto, Kyoto University. Available at: http:// www.pmel.noaa.gov/its2001/Separate_Papers/1-08_ Kawata.pdf [accessed 25 February 2010]

Kreimer, A. (2001) Social and economic impacts of natural disasters, International Geology Review, 43(5), pp. 401405. http://dx.doi.org/10.1080/00206810109465021

Kulatunga, U. (2010) Impact of culture towards disaster risk reduction, International Journal of Strategic 
Property Management, 14(4), pp. 304-313. http:// dx.doi.org/10.3846/ijspm.2010.23

Lawrence, D. L. and Low, S. M. (1990) The built environment and spatial form, Annual Review of Anthropology, 19, pp. 453-505. http://dx.doi.org/10.1146/annurev.an.19.100190.002321

Lizarralde, G. and Boucher, M. (2004) Learning from postdisaster reconstruction for pre-disaster planning. In: Proceedings of the Second International Conference on Post-disaster reconstruction: Planning for Reconstruction, 22-23 April 2004. Coventry University, UK.

McClellan, J. (2006) Hurricane Katrina: Lessons for academic emergency and disaster management degree programs, Journal of Security Education, 1(4), pp. 39-49. http://dx.doi.org/10.1300/J460v01n04_03

McDonald, R. (2003) Introduction to natural and manmade disasters and their effects on buildings. Oxford: Architectural Press.

Niemi, H. (2009) Why from teaching to learning?, European Educational Research Journal, 8(1), pp. 1-17. http://dx.doi.org/10.2304/eerj.2009.8.1.1

Nikhileswarananda, S. (2004) Post disaster reconstruction work in Gujarat on behalf of Ramakrishna Mission. In: Proceedings of the Second International Conference on Post-disaster reconstruction: Planning for Reconstruction, 22-23 April 2004. Coventry University, UK.

OECD (2003) The role of national qualifications systems in promoting lifelong learning: Background report for Ireland. [Online] Ireland, OECD, The National Qualifications Authority of Ireland. Available at: http:// www.oecd.org/dataoecd/41/20/33978011.pdf [accessed 14 April 2011]

OECD (2004) Lifelong learning. [Online] OECD policy brief. Available at: http://www.oecd.org/dataoecd/17/11/29478789.pdf [accessed 10 April 2011]

Ofori, G. (2002) Developing the construction industry to prevent and respond to disasters. In: Proceedings of the First International Conference on Post-disaster reconstruction: Improving post-disaster reconstruction in developing countries, 23-25 May 2002. Universite de Montreal, Canada.

Palliyaguru, R. and Amaratunga, D. (2008) Managing disaster risks through quality infrastructure and vice versa: Post disaster infrastructure reconstruction practices, Structural Survey, 26(5), pp. 426-434. http://dx.doi.org/10.1108/02630800810922766

Pena-Mora, W. (2005) Collaborative first response to disasters involving critical physical infrastructure. O'Neal Faculty Scholar Seminar from University of Illinois, 19 September 2005.

Pourezzat, A. A., Nejati, M. and Mollaee, A. (2010) Dataflow model for managing urban disasters: The experience of Bam earthquake, International Journal of Disaster Resilience in the Built Environment, 1(1), pp. 84-102. http://dx.doi.org/10.1108/17595901011026490

RICS (2011) RICS disaster management commission. [Online] London, Royal Institution of Chartered Surveyors. Available at: http://www.rics.org/site/download_
feed.aspx?fileID=5640\&fileExtension=PDF [accessed 25 February 2011]

Rivera, J. and Miller, D. (2008) Disaster vulnerability education: A new focus on disaster education across the curriculum, Journal of Applied Security Research, 4(1-2), pp. 60-67. http://dx.doi. org/10.1080/19361610802210202

Rouhban, B. (2011) Knowledge management and education for disaster reduction. [Online] The Environment Times. Available at: http://www.grida.no/publications/et/ep3/ page/2618.aspx [accessed 25 February 2011]

Seneviratne, K., Baldry, D. and Pathirage, C. (2010) Disaster knowledge factors in managing disaster successfully, International Journal of Strategic Property Management, 14(4), pp. 376-390. http://dx.doi. org/10.3846/ijspm.2010.28

Sevin, E and Little, R. (1998) Mitigating terrorist hazards, The Bridge, 28(3), pp. 156-172.

Shaw, R. (2008) Higher education in environment and disaster management. [Online] Kyoto, Kyoto University. Available at: http://www.auedm.net/Data/ activities/1st\%20Workshop/Workshop/Rajib\%20 Shaw\%20AUEDM\%20Presentation.pdf [accessed 25 February 2011]

Smith, K. (2004) Environmental hazards. $4^{\text {th }}$ ed. London and New York: Routledge.

Thayaparan, M., Siriwardena, M., Malalgoda, C., Amaratunga, D., Kaklauskas, A. and Lill, I. (2010) Reforming HEI to improve skills and knowledge on disaster resilience among construction professionals. In: The Proceedings of the Construction, Building and Real Estate Research Conference of the Royal Institution of Chartered Surveyors (COBRA), 2-3 September 2010. Dauphine Université, Paris.

USGS (2011) Largest and deadliest earthquakes by year 1990-2011. [Online] United States Geological Survey. Available at: http://earthquake.usgs.gov/earthquakes/eqarchives/year/byyear.php [accessed 13 May 2011]

Warfield, C. (2004) The disaster management cycle. [Online] Kobe, The Global Development Research Centre. Available at: http://www.gdrc.org/uem/ disasters/1-dm_cycle.html [accessed 15 April 2010]

World Bank (2001) World Bank and Asian Development Bank complete preliminary Gujarat earthquake damage assessment and recovery plan. [Online] India. Available at: http://www.worldbank.org/gujarat; http://www.adb.org/ [accessed 01 January 2007]

Young, I. (2004) Monserrat: Post volcano reconstruction and rehabilitation - A case study. In: Proceedings of the Second International Conference on Post-disaster reconstruction: Planning for Reconstruction, 22-23 April 2004. Coventry University, UK.

Xiaozhou, X. (2001) The role of the university in lifelong learning: Perspectives from the People's Republic of China, Higher Education Policy, 14, pp. 313-324. http://dx.doi.org/10.1016/S0952-8733(01)00027-7 